\title{
Direct and Indirect Effect of Myzus Persicae Infestation on Buildup of Whitefly (Bemisia Tabaci) in Tomato Crop under Laboratory Conditions
}

By Khadija Javed, Humayun Javed \& Dewen Qiu

Pir Mehr Ali Shah Arid Agriculture University

Abstract- The tomato crop is affected by a number of pests in the world as well as in China and Pakistan. The whitefly (Bemisia tabaci) is considered a very serious and damaging pest of tomato crop along with many other vegetables and field crops. Population buildup of whitefly is affected by many factors, including biotic and a biotic. One of the factors affecting the whitefly population in the tomato crop is green peach aphid (Myzus persicae) infestation before the whitefly attack. This project designed to note the direct and indirect effect of Myzus persicae infestation on the population setup of whitefly in tomato crops. The results revealed that whitefly prefers tomato plants without having aphids on them (choice) and can be settled on the tomato plants also when there are aphids present (no choice). The period after aphid infestation have a negative effect on the whitefly population, and the density of aphids/leaf has also influenced the whitefly population.

Keywords: whitefly, myzus persicae, bemisia tabaci, tomato, induced resistance.

GJSFR-D Classification: FOR Code: 070199

Strictly as per the compliance and regulations of:

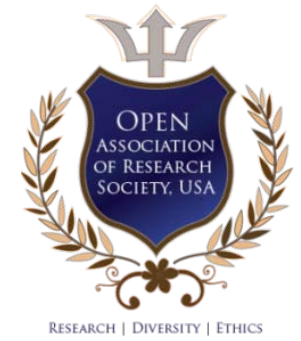

(c) 2020. Khadija Javed, Humayun Javed \& Dewen Qiu. This is a research/review paper, distributed under the terms of the Creative Commons Attribution-Noncommercial 3.0 Unported License http://creativecommons.org/licenses/by-nc/3.0/), permitting all non commercial use, distribution, and reproduction in any medium, provided the original work is properly cited. 


\title{
Direct and Indirect Effect of Myzus Persicae Infestation on Buildup of Whitefly (Bemisia Tabaci) in Tomato Crop under Laboratory Conditions
}

\author{
Khadija Javed $^{\alpha}$, Humayun Javed ${ }^{\sigma} \&$ Dewen Qiu ${ }^{\rho}$
}

\begin{abstract}
The tomato crop is affected by a number of pests in the world as well as in China and Pakistan. The whitefly (Bemisia tabaci) is considered a very serious and damaging pest of tomato crop along with many other vegetables and field crops. Population buildup of whitefly is affected by many factors, including biotic and a biotic. One of the factors affecting the whitefly population in the tomato crop is green peach aphid (Myzus persicae) infestation before the whitefly attack. This project designed to note the direct and indirect effect of Myzus persicae infestation on the population setup of whitefly in tomato crops. The results revealed that whitefly prefers tomato plants without having aphids on them (choice) and can be settled on the tomato plants also when there are aphids present (no choice). The period after aphid infestation have a negative effect on the whitefly population, and the density of aphids/leaf has also influenced the whitefly population. Indirect effects reduced after removal of aphid infestation, and so, whitefly settlement significantly increased on such plants. Our study suggests that the host plants can induce secondary metabolites after an early infestation of Myzus persicae. This can utilize in ecological pest management by manipulating the whitefly behavior through aphid infestations.
\end{abstract}

Keywords: whitefly, myzus persicae, bemisia tabaci, tomato, induced resistance.

\section{InTRODUCTION}

T omato whitefly (Bemisia tabaci Genn.) belonging to the order Hemiptera and family Aleyrodidae, is considered as a major threat to crops. Whitefly is responsible to transmit many types of viruses in field crops as well as in vegetables (Jones, 2003; Oliveira et al., 2001). Many biotypes of whitefly have reported as economic pests throughout the world. A well-known biotype $B$ of $B$. tabaci is a major pest of beans, cotton, tomato, leafy vegetables, and soybean throughout the world were causing worth 714 million dollar losses per year (Oliveira et al., 2013; Fontes et al., 2012). Similarly, the aphid is also a devastating pest of a wide range of

Author a $\rho$ : The State Key Laboratory for Bio-Pesticides Engineering of Plant Disease Biocontrol and Insect Pests, Institute of Plant Protection, Chinese Academy of Agricultural Science, No. 12 Zhong-Guan-Cun South Street, Beijing 100081, China. e-mail: Qiudewen@caas.cn Author o: Department of Entomology, Pir Mehr Ali Shah Arid Agriculture University, Rawalpindi, Pakistan. crops grown in greenhouses like pepper, tomato, and cucumber. Sitobion avenae, Rophalosiphum padi, Schizaphis graminum, Metopolophium dirhodum are reported species of aphid, causing severe damage to a large number of field crops and vegetables (Dana, 2006). Aphid and whitefly rapidly increase their populations and are mostly found in overlapping generations. Insecticides are used as the first choice to control these pests in greenhouses and field crops (Castle et al., 2014). Resultantly, resistance, resurgence, and finally, high input costs have reported due to increasing use of insecticides at higher doses. Farmers are facing problems due to individuals continuously selected as resistant (Longhurst et al., 2013; Basit et al., 2013).

Like many other crops, green peach aphid, Myzus persicae, attacks tomato. $M$. persicae, has reported from all around the world including Pakistan. $M$. persicae is an important pest in many areas of the world due to transmission of diseases and plant viruses. $M$. persicae can survive under wide range of environmental conditions in greenhouses as well as in open fields. The aphid is disseminated to other parts of a country through transportation, winds, and storms. It has a wide range of host plants, including tomato as a major host, due to which it can survive better as compared with other species (Heathcote 1962). Green peach aphid can survive on hardy plants and weeds during summer and reproduce under favorable conditions creating problems for key crops and vegetables (Tamaki 1975, Tamaki and Fox 1982). Essential weed hosts of this species include pigweed, Chenopodium album, Convolvulus arvensis, Amaranthus retroflexus and bindweeds (Annis et al. 1981).

Interspecific interactions between whiteflies and other herbivore insect species are present because of the wide host range of whitefly. Many chemical and behavioral changes have recorded when two different species of insects are feeding on the same host plant. Such interactions have also recorded between whitefly and the cabbage loopers (Inbar et al. 1999). There are reports that population of whitefly on tomato was negatively affected in the presence of Liriomyza trifolii 
Burgess (Zhang et al. 2005). These negative impacts on the population of other species are due to a reduction in the quality of plant sap after the attack of former species (McClure 1980, Olmstead et al. 1997). Studies have shown that aphids are significantly responsible for lowering the quality of plant sap and decreasing the concentration of chlorophyll (Ni et al. 2001,2002). Layla and Al-Shareef (2011) reported that whitefly could reduce plant sap and chlorophyll pigment up to $36 \%$, which may deter the populations of secondary pests. These types of plant reactions and behavioral changes are known as induced resistance or acquired resistance and confined only to the previous invader or its activity. Arguing on the terminology, researchers agree to define these elicited responses used to protect plants against pests and diseases as induced resistance (Hammerschmidt et al. 2001). Some insects, bacteria, fungi, and viruses are eligible to induce resistance in plants against other insect pests and pathogens (Hammer schmidt et al., 200, Agrawal; et al. 1999, Siddiqui \& Shaukat, 2004).

Expected outcomes form the present experimental study focuses on to confirm and evaluate these interactions in the presence of B.tabaci and M.persicae on, the same host (tomato).

\section{il. Materials and Methods}

\section{a) Plant Materials}

Tomato seeds of different varieties were collected from the laboratory of bio pesticides at the Chinese Academy of Agricultural Sciences, Beijing, China, and sown in seedling trays using peat moss for seed germination. All the necessary care followed for germination and growth of seedlings. After 35 days of seed germination, tomato plants shifted in black color plastic pots with the depth of $25 \mathrm{~cm}$ and diameter $20 \mathrm{~cm}$ these potted plants were kept in $2 \mathrm{ft} \times 2 \mathrm{ft}$ clean cages properly covered with an insect net. When these plants reached to $35 \mathrm{~cm}$ height with 8 to 10 healthy leaves, then bioassays were started. During experimentation, temperature and relative humidity were at $25 \pm 2 \mathrm{C}^{\circ}$ and $65 \pm 5 \%$ respectively. The photo period was adjusted to 16:8 (L:D) with the help of artificial lights in each cage.

\section{b) Insect Materia/s}

Aphids (Myzus persicae) were collected from cabbage leaves in greenhouse conditions at the Chinese Academy of Agricultural Sciences, Beijing, China and this population was maintained on the same variety of cabbage grown in plastic pots, and caged with nylon nets in the laboratory conditions. These aphids reared up to five generations, and fourth in star aphids used for infestation on tomato plants and leaves during the bioassays.

Whitefly (Bemisia tabaci) population (mix of male and female) collected from the tomato crop grown at a chamber in green house conditions at the Chinese
Academy of Agricultural Sciences, Beijing, China, and reared up to generations in the same laboratory conditions as mentioned above. The equal number of male and female whiteflies was chosen for experimentation.

\section{c) Bioassays}

Two types of experiments were conducted, one for monitoring the direct effects and second for the indirect effects. The direct effects monitored in the presence of aphid on the tomato plants, and indirect effects monitored when the infestation aphids removed from the tomato plant. For choice and no-choice experiment, whole plants used but for factorial observation, detached leaves used. The white fly adults (10 pairs) were collected from the rearing colony and released in the study cages for each treatment in every experiment. The settlement of white fly adults after each 30 minutes observed without any disturbance. This observation continued up to 10 hours after releasing the whitefly adults. The percentage of settled white flies used for purpose of record keeping and analysis. There total 40 cages for each treatment of all eight experiments, and these four cages counted as four replicates (mean of each 10 cages as one replicate).

\section{d) Data Analysis}

The data was collected and arranged on Microsoft excel for calculation of means and averages. The data was analyzed using the statistix 8.1 for analysis of variance, and mean percentages compared through LSD $(P=0.05)$. In first four experiments, the data of last observation $\left(10^{\text {th }} \mathrm{h}\right)$ subjected for analysis.

\section{Results}

\section{a) Aphid's infestation impact on Bemisia tabaci}

This study has shown significant results regarding the association between the aphid infestation and whitefly population (Figures 1 to 4 ). The effect of infestation interval was significant $(F=8.04 \& P=0.02)$ on the population of the whitefly adults attracted toward the infested plants. After 10 hours of the white fly adults release, the maximum number (41.25\%) of the white fly adults were settled on the tomato plants with a minimum interval of an aphid infestation (24h). 32.50\% adult of whiteflies was sitting on leaves infested by aphids for 48hours followed by the minimum percentage of $30 \%$ for 72 hour infested plants but non-significant with $48 \mathrm{~h}$, infested plants as shown in figure 1. Moreover, the impact of aphid density on whitefly was also significant $(F=4.84, P=0.0561)$ with maximum white fly settlement (41.25\%) on an infected plant by $50 a p h i d / p l a n t$ followed by the $37.50 \%$ whiteflies on aphid density of 25/plant. While the minimum whitefly population (30\%) was settled on aphid density of 75/ plants as shown in figure 2 . 
The impact of time duration after releasing the white fly on aphid infested plants after removing the aphids was slightly significant $(F=4.47, \mathrm{P}=0.06)$ with the maximum population (36.25\%) after 48 hours of aphid removal followed by the $27.5 \%$ just after removal of preinfesting aphids. The minimum whitefly population (23.75\%) settled after 24 hours of per-infesting aphid removal (Figure 3). There was non-significant ( $F=0.53$, $P=0.61$ ) impacts on the white fly population on the grounds of leaf position referred with infested one (Figure 4).

b) Whitefly population fluctuation in Choice and NoChoice Experiments

\section{i. Direct Effect}

The direct effect of aphid infestation observed in the presence of aphid (pre-infested), and the experiment showed highly significant $(F=95.53, P=0.00)$ influence on white fly population. The highest population (41.25\%) observed in results of no-choice given to whitefly adults on plants infested with aphids followed by the aphid free plants when there was choice i.e., 37.81\%. In all cases of choice and no choice, there was less settlement of whitefly population in non-infested plants, but the percentage increased on aphid free plant when there was a choice given to the white fly population, as shown in figure 5. The trend of whitefly population settlement has shown in figure 6 with half-hour interval between every two observations. The trend is revealing that the direct effect of aphid infestation keeps the whitefly population in choice as compared with the no-choice experiments.

\section{ii. Indirect Effect}

The highly significant $(F=48.18, \quad P=0.00)$ influence of aphid infestation after removal of aphids was observed in both options of choice and no-choice, as shown in figure 7 . The high population settled on the aphid infested plant after their removal (indirect effect) containing $47.5 \%$ population when there was no-choice followed by the $38.25 \%$ population in aphid infested plants with the choice to choose pre infested plant or non-infested plants. These results cleared that whitefly response towards the aphid infestation was variable, especially in case of an indirect effect. The population settlement of the white fly population was higher in choice given as compared with the treatments with nochoice treatment as shown in figure 04. Initially, B. tabaci settlement difference was less after the release of adults in cages with choice and no choice, but with the passage of time, this difference was increased up to 10th hours of whitefly adults release.

\section{Discussion}

The results of the present study proved that there is an interaction between insect behavior, and plant odors and this phenomenon used as a tool for the pest management in the coming days. The same behavior of the plant-eating insects have described by Tosh and Brogan (2015) that plant volatiles are useful for pest management and harmless to the end consumers if used in pest management programs. The actual thing is to create confusion effect between host plant and the whitefly feeding on tomato plant, which can be produced by application of volatiles compounds or induction through pre-infestation of other pests like a green peach aphid. This study also proved that resistance in tomato plants was successfully induced against Bemisia tabaci through pre-infestation of Myzus persicae@50 aphids per plant. The similar findings observed by Agrawal et al. (2000) that the whitefly population in the crop was directly or indirectly negatively affected through the pre-infestation of spider mites crossing 30 mites approximately. The similar studies of Wool and Hales (1996), Quiroz et al., (1997), Sauge et al., (2002) and Messina et al., (2002), also presented the induced resistance by Myzus persicae, the same species as in this study. There were some other studies, which show negative impacts or limited impact on the subsequent infestation of the pre-infested plant by the same aphid species (Messina et al., 2002).

According to the expected outcomes in our study suggested, that population settlement of whitefly was higher throughout the observational period in case of the choice experiment after infestation with green peach aphid. The Sauge et al. (2002), who found that the pest population enhanced slightly, observed the similar results. $10-15 \%$ higher growth rate of S. Exigua larvae reported when it was fed on pre-infested leaves by $M$. Persicae, similar to our indirect effect experiment results (Stout et al. 1998). Different plant responses reviewed by Thompson And Goggin (2006), depending on the pest species, density, and infestation interval, which reveals that the mechanism of induced resistance was not clear, the similar impact of our study has recorded that exact figures can't be given for response of whitefly on tomato plant infested with green peach aphid. In some cases, research outcomes revealed that pre-infestation reduces plant quality for whitefly as reported by Wool and Hales (1996), but with an increase of aphid population not supported because of induced resistance as it might cause some initial damage to the crop. There was beneficial interaction between tomato plants and the aphid infestation through induction of resistance against the whitefly, but in some cases, it was negative for the tomato crop in accordance with ZhuSalzman et al., (2005).

\section{Conclusion}

We may conclude that the pre-infestation of Myzus persicae on tomato plants has direct and indirect impacts on Bemisia tabaci and its population settlement. The duration of infestation screened out as a major 
factor affecting the whitefly population, followed by the density of pre-infesting aphids/leaf. There was a higher population of whitefly in choice on pre infested tomato plant as compared with the non-choice experiments. The current study has presented a brief insect-plant interaction against whitefly as a considerable tool for the pest management. The research study provided an important understanding regarding host selection, and population buildup by the whitefly, which will be helpful in future for the integrated pest management in tomato crop.

\section{References Références Referencias}

1. Basit, M., Saeed, S., Saleem, M.A. and Sayyed, A.H. 2013. Can resistance in Bemisiatabaci (Homoptera: Aleyrodidae) be overcome with mixtures of neonicotinoids and insect growth regulators. Crop Protection 44:135-141.

2. Castle, S.J., Merten, P. and Prabhaker, N. 2014. Comparative susceptibility of Bemisia tabaci to imidacloprid in field- and laboratory-based bioassays. Pest Management Science, Wiley Online Library.

3. Dana, M., Gh. S., Felicia M., Elena, N., Maria, S., 2006. Integrated agroecological control of wheat aphids and cicades, standing for environment agriculture sustainable development interrelation, in Transylvania. Buletin USAMV-CN, 62, (80-85).

4. Fontes, F.V.H.M., Colombo, C.A., Lourenção, A.L., 2012. Structure of genetic diversity of Bemisiatabaci (Genn.) (Hemiptera: Aleyrodidae) populations in Brazilian crops and locations. Sci. Agric. 69 (1), 47-53.

5. Jones, D.R., 2003. Plant viruses transmitted by whiteflies. Eur. J. Plant Pathol. 109, 195-219.

6. Longhurst, C., Babcock, J.M., Denholm, I., Gorman, K., Thomas, J.D. and Sparks, T.C. 2013. Crossresistance relationships of the sulfoximine insecticide sulfoxaflor with neonicotinoids and other insecticides in the whiteflies Bemisiatabaci and Trialeurodesvaporariorum. Pest Management Science 69 (7):809-813.

7. Oliveira, C.M., Auad, A.M., Mendes, S.M., Frizzas, M.R., 2013. Economic impact of exotic insect pests in Brazilian agriculture. J. Appl. Entomol. 137, 1-15

8. Oliveira, M.R.V., Henneberry, T.J., Anderson, P., 2001. History current status and collaborative research projects for Bemisia tabaci. Crop Prot. 20, 709-723.

9. Annis B, Tamaki G, Berry RE. 1981. Seasonal occurrence of wild secondary hosts of the green peach aphid, Myzus persicae (Sulzer), in agricultural systems in the Yakima Valley. Environmental Entomology 10: 307-312.

10. Tamaki G. 1975. Weeds in orchards as important alternate sources of green peach aphids in late spring. Environmental Entomology 4: 958-960.
11. Tamaki G, Fox L. 1982. Weed species hosting viruliferous green peach aphids, vector of beet western yellows virus. Environmental Entomology 11: 115-117.

12. Heathcote GD. 1962. The suitability of some plant hosts for the development of the peach-potato aphid, Myzus persicae (Sulzer). Entomologica Experimentalis et Appliciata 5: 114-118.

13. Inbar, M., Doostdar, H., Leibee, G. L. \& Mayer, R. T. The role of plant rapidly induced responses in asymmetric interspecific interactions among insect herbivores. J. Chem. Ecol. 25, 1961-1979 (1999).

14. Zhang, L. P., Zhang, G. Y., Zhang, W. J. \& Liu, Z. Interspecific interactions between Bemisia tabaci (Hem. Aleyrodidae) and Liriomyzasativae (Dipt. Agromyzidae). J. Appl. Entomol. 129, 443-446 (2005)

15. McClure, M. S. Competition between exotic species: scale insects on hemlock. Ecology 61, 1391-1401 (1980).

16. Olmstead, K. L., Denno, R. F., Morton, T. C. \& Romeo, J. T. Influence of Prokelisia plant hoppers on the amino acid composition and growth of Spartina alterniflora. J. Chem. Ecol. 23, 303-321 (1997).

17. Ni X, Quisenberry SS, Heng-Moss T, Markwel J, Higley L, Baxendale F, Sarath G, Klucase R. 2002. Dynamics change in photosynthetic pigments and chlorophyll degradation elicited by cereal aphid feeding. Entomol. Exp. Appl., 105: 43-53.

18. Ni X, Quisenberry SS, Markwell J, Heng-Moss $T$, Higley T, Baxendale F, Sarath G, Klucas R. 2001. In vitro enzymatic chlorophyll catabolism in wheat elicited by cereal aphid feeding. Entomol. Exp. Appl., 101: 159-166.

19. Layla AH. Al-Shareef. 2011. Impact of whitefly, Bemisiatabaci (Gennadius) infestation on chlorophyl and carotene cocentrations, as well as moisture content in some vegetable plants in a greenhouse. Egypt. J. Exp. Biol. (Zool.), 7(1): 11 - 15 (2011)

20. Hammerschmidt, R., Metraux, J.P. \& van Loon, L.C. (2001) Inducing resistance: a summary of papers presented at the First International Symposium on Induced Resistance to Plant Diseases, Corfu, May 2000. European Journal of Plant Pathology 107, 1-6.

21. Agrawal, A., Tuzun, S. \& Bent, E. (1999) Induced Plant Defenses against Pathogens and Herbivores. 390 pp. St. Paul, Minnesota, APS Press.

22. Siddiqui, I.A. \& Shaukat, S.S. (2004) Systemic resistance in tomato induced by biocontrol bacteria against the rootknot nematode, Meloidogyne javanica is independent of salicylic acid production. Journal of Phytopathology 152, 48-54.

23. Tosh, C. R., \& Brogan, B. (2015). Control of tomato whiteflies using the confusion effect of plant 
odours. Agronomy for sustainable development, 35(1), 183-193.

24. Cao, H. H., Liu, H. R., Zhang, Z. F., \& Liu, T. X. (2016). The green peach aphid Myzus persicae perform better on pre-infested Chinese cabbage Brassica pekinensis by enhancing host plant nutritional quality. Scientific reports, 6, 21954.

25. Agrawal, A., Karban, R. \& Colfer, R.G. (2000) How leaf domatia and induced plant resistance affect herbivores, natural enemies and plant performance. Oikos 89, 70-80.

26. Wool, D. \& Hales, D.F. (1996) Previous infestation affects recolonization of cotton by Aphis gossypii: induced resistance or plant damage? Phytoparasitica 24, 39-48.

27. Quiroz, A., Petterson, J., Pickett, J.A., Wadhams, L.J. \& Niemeyer, H.M. (1997) Semiochemicals mediating spacing behavior of bird cherry-oat aphid, Rhopalosiphumpadi feeding on cereals. Journal of Chemical Ecology 23, 2599-2607.
28. Sauge, M.H., Lacroze, J.P., Poe“ssel, J.L., Pascal, T. \&Kervella, J. (2002) Induced resistance by Myzus persicae in the peach cultivar 'Rubira'. Entomologia Experimentalis et Applicata 102, 29-37.

29. Messina, F.J., Taylor, R. \& Karren, M.E. (2002) Divergent responses of two cereal aphids to previous infestation of their host plant. Entomologia Experimentalis et Applicata 16, 43-50.

30. Stout, M.J., Workman, K.V., Bostock, R.M. \& Duffey, S.S. (1998) Specificity of induced resistance in the tomato, Lycopersiconesculentum. Oecologia 113, 74-81.

31. Zhu-Salzman, K., Bi, J.L. \& Liu, T.X. (2005) Molecular strategies of plant defense and insect counter-defense. Insect Science 12, 3-15.

32. Thompson, G.A. \& Goggin, F.L. (2006) Transcriptomics and functional genomics of plant defence induction by phloem-feeding insects. Journal of Experimental Botany 57, 755-766.

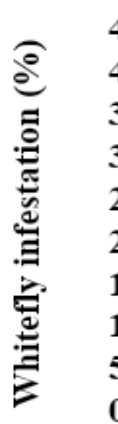

Fig. 1

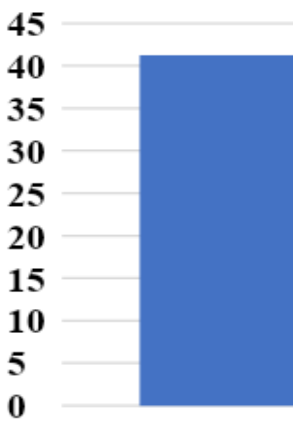

24

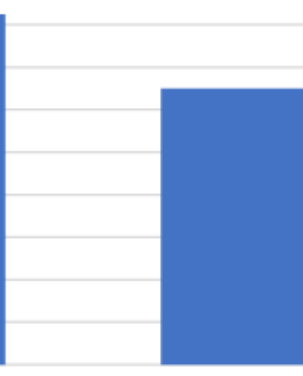

48

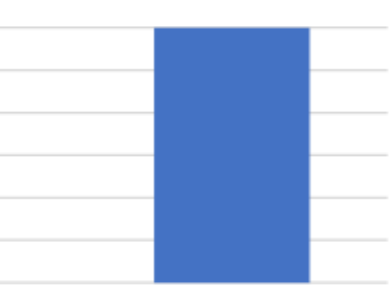

72

Time duration (hours)

Fig. 1: Effect of infestation interval on the population of whitefly adult attracted toward the infested plants

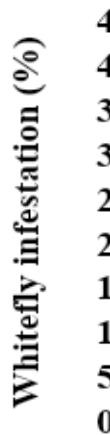

Fig. 2

$$
\begin{aligned}
& 45 \\
& 40 \\
& 35 \\
& 30 \\
& 25 \\
& 20 \\
& 15 \\
& 10 \\
& 5 \\
& 0
\end{aligned}
$$

25

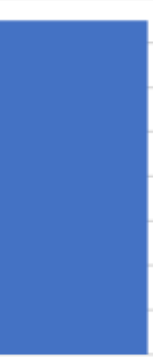

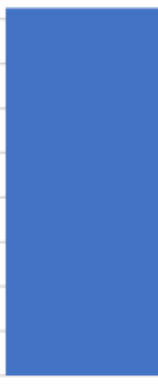

50

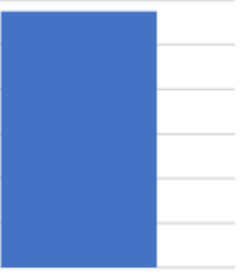

75

Aphid density/plant

Fig. 2: Effect of aphid density on the population of whitefly adult attracted toward the infested plants 


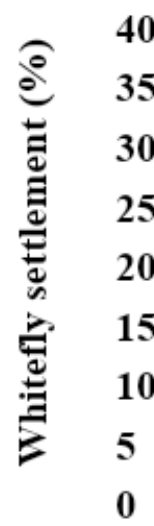

Fig. 3

$$
\begin{aligned}
& 40 \\
& 35 \\
& 30 \\
& 5 \\
& 0 \\
& 15 \\
& 10 \\
& 5
\end{aligned}
$$

Fig. 3: Effect time duration after releasing the white fly on aphid infested plants after removing the aphids

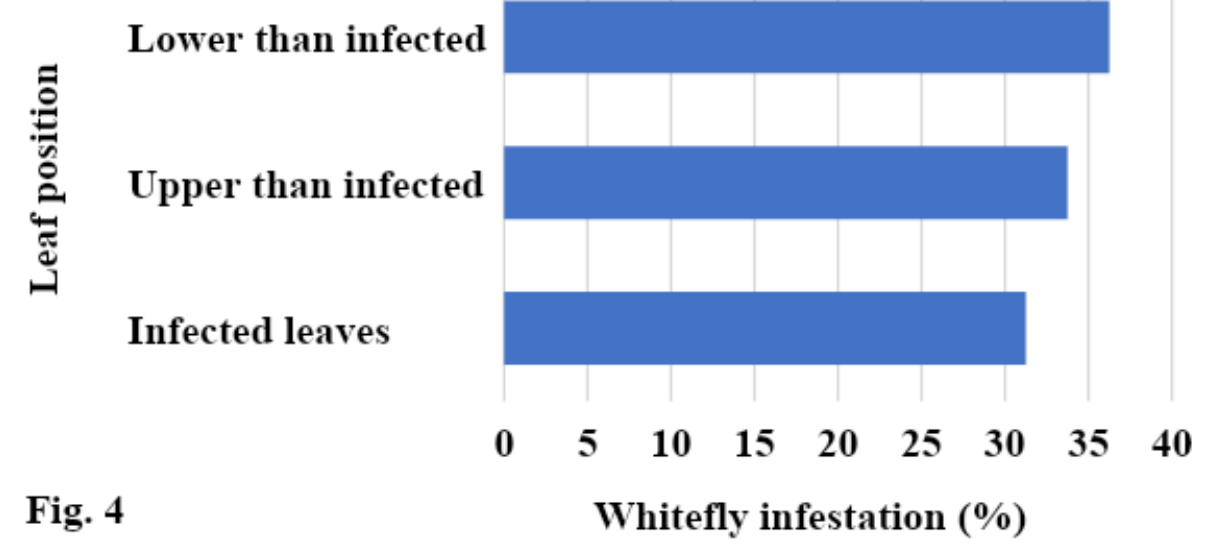

Fig. 4: Effect of leaf position on white fly infestation 


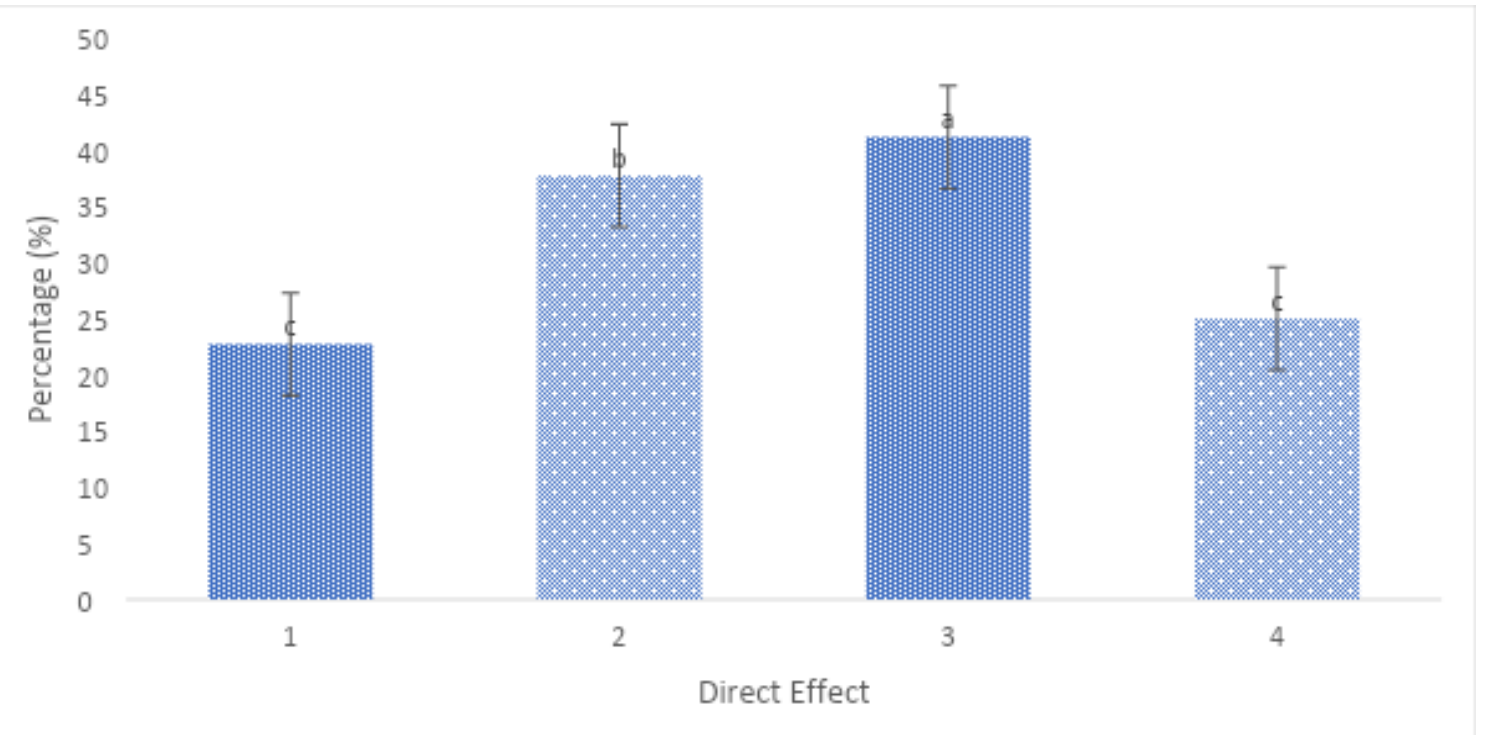

Fig. 5: Mean percentages of whitefly adults on treated and untreated plants with aphids (direct effects)

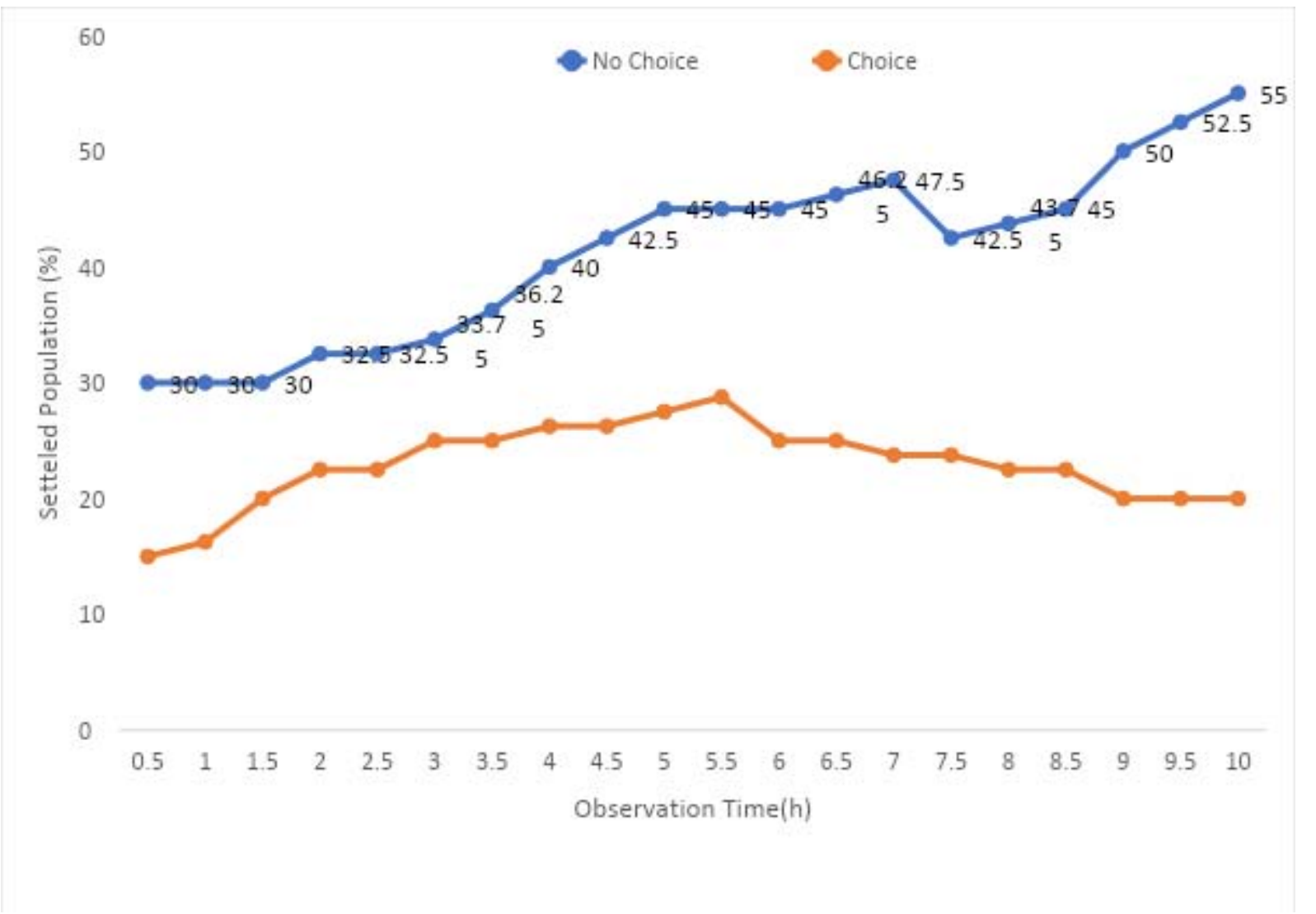

Fig. 6: Mean percentages whitefly adults on treated leaves over different observation times in direct leaves with aphids) bioassays 


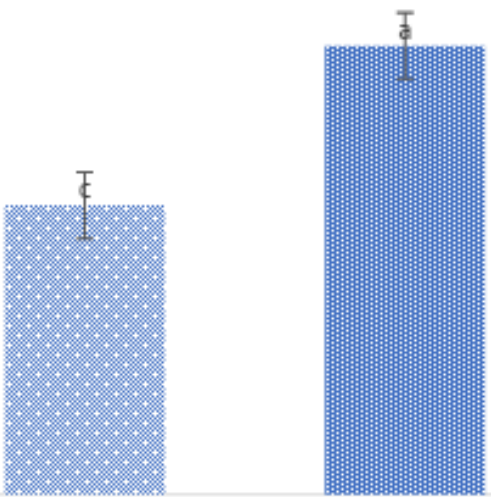

Indirect Effect 3

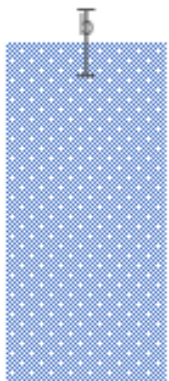

4

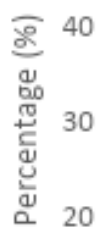

10

0

1

Fig. 7: Mean percentages of whitefly adults on treated and untreated plants after removal of aphids infesting the leaves (indirect effect)

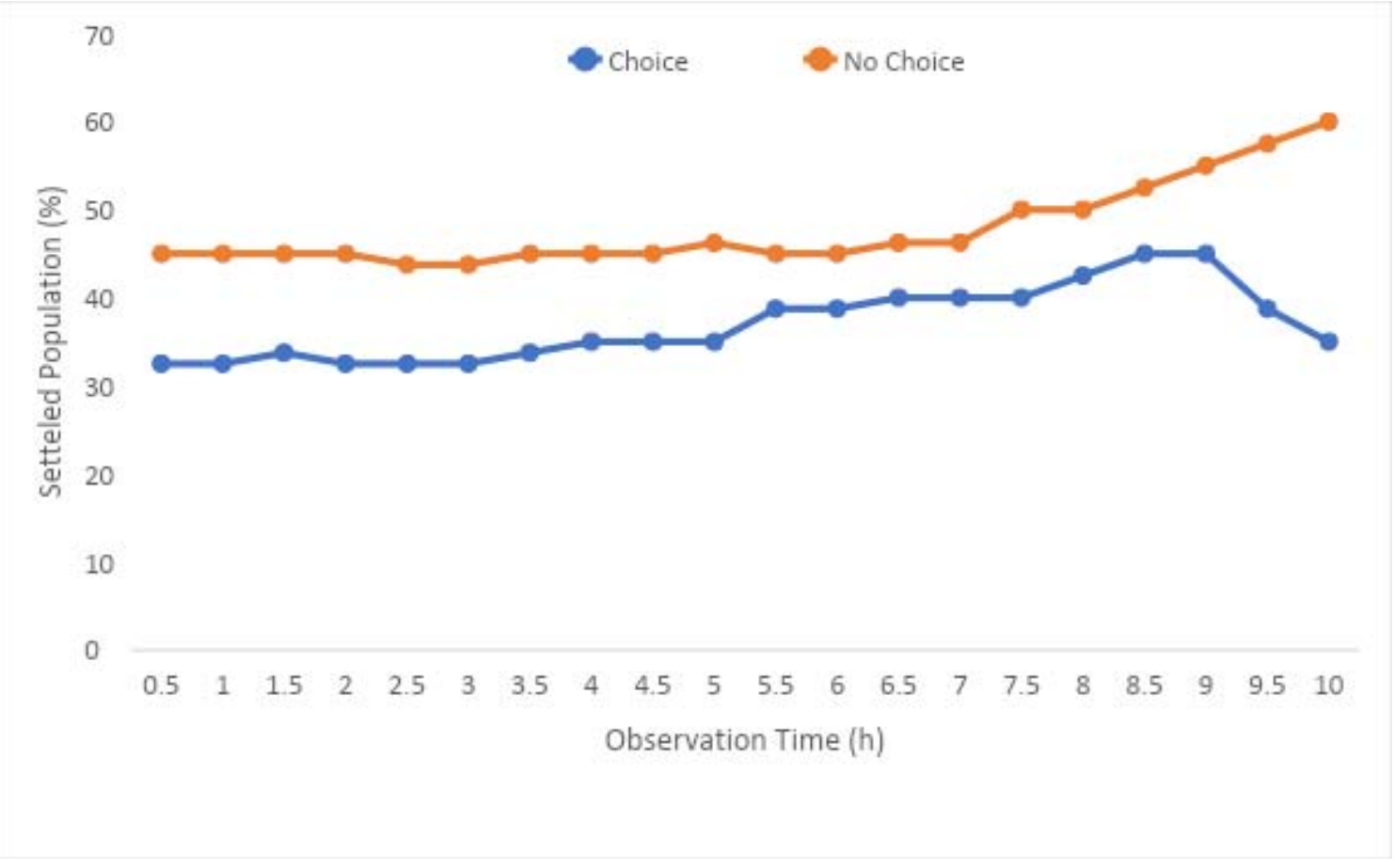

Fig. 8: Mean percentages whitefly adults on treated leaves over different observation times in indirect (leaves after removing the aphids) bioassays 